\title{
Associations of Jet Streams with Tornado Outbreaks in the North America
}

\author{
Igor G. Zurbenko, Mingzeng Sun \\ Department of Epidemiology and Biostatistics, State University of New York at Albany, New York, USA \\ Email: igorg.zurbenko@gmail.com, mzsun99@gmail.com, msun@albany.edu
}

Received 16 June 2015; accepted 24 July 2015; published 27 July 2015

Copyright (C) 2015 by authors and Scientific Research Publishing Inc.

This work is licensed under the Creative Commons Attribution International License (CC BY). http://creativecommons.org/licenses/by/4.0/

(c) (i) Open Access

\begin{abstract}
Jet streams, a current of fast winds located about seven miles up near the tropopause, are major weather driving factors in the mid-latitudes. Using the Modern-Era Retrospective Analysis for Research and Applications (MERRA) reanalysis data resources for the period 1979 to 1988, we defined the latitudinal distribution of daily wind maxima by month, and analyzed latitudinal distribution of the highest daily wind speed at the selected longitude in the $19^{\text {th }}$ week of the year. We showed the typical diving pattern of jet stream over Central America in spring. We found that latitudinal distribution of daily wind maxima was concurrently oscillated with latitudinal distribution of tornado outbreaks in April, May and June. KZ filter smoothed latitudinal distribution of highest daily wind speed on tornado days showed a substantial increase in number of daily wind maxima over tornado alley region, compared to that on non-tornado-days.
\end{abstract}

\section{Keywords}

Jet Stream, Tornado, KZ Filter, Specific Humidity

\section{Introduction}

\subsection{Water Vapor-One of the Key Driven Factors of Jet Stream}

Water vapor is considered as major source of dynamics in atmospheric processes. Tropical area is receiving major part of sun radiation and is working as an essential vapor generator over our planet [1]. That permanent generation of extra mass in tropical atmosphere causes concentration of vapor mass at tropics to be about $2 \%$ higher than at higher latitudes, causing approximately the same degree drop in air pressure at higher latitudes; which in turn causes tropical air mass expansion and transmission to higher latitudes in both North and South directions. In northern hemisphere, this air transport to the cold North is causing extra precipitations with essential shrinkage of vapor and further contributing to air mass transport to higher latitudes. In mid-latitudes those 
transmissions will be knocked out to the east by rapidly increasing Carioles force. This effect is causing strong atmospheric current at mid-latitudes in the east direction (jet stream). There are permanent equatorial trade winds and water currents in the west direction; which can be explained by astronomic gravity forces and rotation of the Earth in east direction [2]. Trade winds will create elevated levels of water vapor concentrations along longitudes at the west side of the Pacific and Atlantic oceans. There was substantial increase in those patterns in last few decades [1]. Thus west side of the oceans will be creating stronger expansion of the air mass to higher latitudes. In the higher latitudes jet stream will be main contributor of shift of air mass to the east direction. In the summer time water vapor generation is very weak at the east cold side of the Pacific (Figure 1), which is making opportunity to close clockwise transport in the North Pacific. North American continent is facing downwards transport at the west coast of cold and dry air, and upwards transport of warm and humid air at Atlantic. This will cause fluctuation of eastwards jet stream current to the South over American continent and enhance strong mechanism of energy exchange between warm and cold air mass. This effect is enhanced by very low tropical vapor transport to the North over continental areas of Mexico. But cold and dry air of jet stream from the North is making "synoptic explosions" when it approaches warm waters of Gulf of Mexico. Directions of long term changes in patterns described above may cause further intensifications in extreme weather effects.

SH : long term average: summer $(6,7,8)$

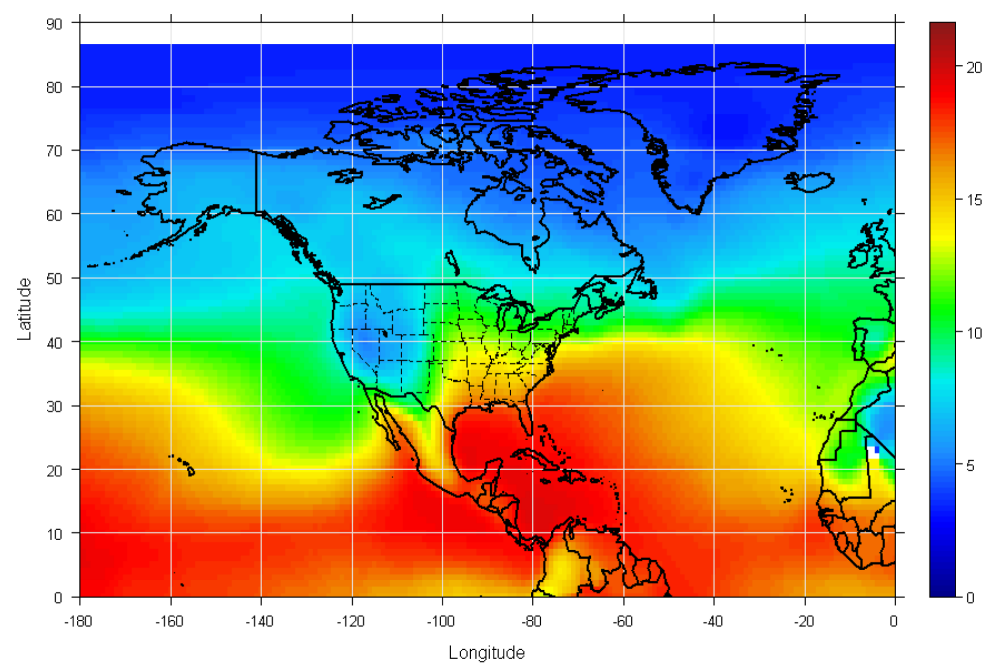

SH : long term average: winter $(12,1,2)$

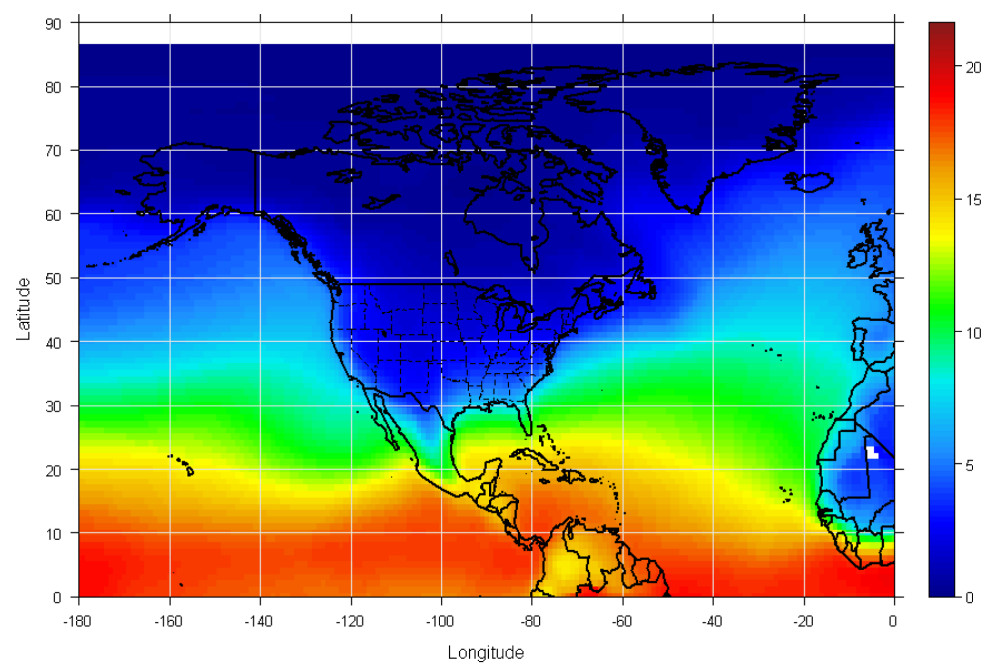

Figure 1. Spatial distribution of average specific humidity from 1973 onwards. 


\subsection{Jet Stream Trajectory-A Reflection of the Dynamic Distribution of Specific Humidity (SH)}

The jet stream is like a river of wind high above (about 7 miles) in the atmosphere where the troposphere meets the stratosphere at a boundary called tropopause. Driven by the meteorological factors mentioned above, jet streams are typically meandering from west to east, often traveling meridionally a very winding path (ridges and troughs), and their width is relatively narrow compared to their length; they can break off at times and merge again "downstream" eventually. Jet streams affect weather patterns world widely, because the strong winds can rapidly push weather systems from one area to another. Meteorologists track the position of jet streams to help predict the weather.

Jet streams shift throughout the year. The seasons of the year, air pressure systems, air humidity and air temperature all affect the trajectory a jet stream travels. During major cold outbreaks over the USA, the jet stream often dives south—staying above the warm-cold boundary—sometimes moving well over the Gulf of Mexico, displaying a typical " $V$ " shape. During unusually mild winter weather and during the summer, the jet stream retreats northward into Canada. In general, jet streams tend to be strongest in winter and spring, because differences of temperature and humidity between the competing Arctic and tropic air masses are greatest at that time. Strong energy exchange in the jet stream current is making strong synoptic disturbances as thunderstorms, floods and tornados.

In our previous study, when applying $\mathrm{KZ}_{\mathrm{m}=(3,3), \mathrm{k}=4}$ to spatially smooth specific humidity data, derived from marine database of the International Comprehensive Ocean-Atmosphere Dataset (ICOADS) and NRT (NCEP Real-time) Marine Observations, Enhanced dataset, an average of specific humidity over USA was calculated in Figure 1, more details can be found in [1].

Figure 1 largely represents the average SH pattern over USA and the around area in summer (top panel) and winter (bottom panel). For example in summer, the difference between equator and mid latitude is at least 10 units of SH (g water vapor $/ \mathrm{kg}$ of air mass). This is indicating that a certain volume of collapse (corresponding to at least 10 units of $\mathrm{SH}$ ) due to vapor vanish, while the air mass is transporting from equator to mid-latitudes at the same temperature; Actual decrease of temperature from equator to higher latitude will make this volume shrinkage only stronger. Amount of collapse vapor is providing energy transferring with coefficient of water to vapor above 300 calories/gram. Transport of air mass to north, coupled with carioles effect, will give essential bust of speed of that air mass to east, and eventually form the eastward jet stream. However, transport itself is uneven in longitudes because of continents and varied by season due to uneven solar energy supply (top panel, Figure 1).

For North America at both east and west sides, there are stronger transport of air mass to north and weaker transport along the continent driven by the natural patterns in water vapor. That makes diving " $V$ " pattern for jet stream over USA at the "right" time. While jet streams reaching Mexican Regions, collision of cold dry air and heat moist air would cause strong synoptic problems, including tornado development.

\subsection{Persistent Presence of Jet Stream-A Key Culprit in the Formation of Tornados}

Jet stream has been believed to be associated with tornado outbreaks [3] [4]. The evidence for the risks of jet stream for tornado development is inclusive, however. For example, we only viewed weather experts' claims, explanations for individual tornado cases, and medium reports [5] [6]; but there has been lack of a clear numerical support to evidence their relations between tornado development and jet streams.

Given that 54\% of tornados developed in spring in Texas [7], it is reasonable to assume that most of the tornados in Central of America occurs in spring and early summer. It would be in good agreement with the distributions in summer of average air SH, a key driven factor for jet streams. Those unevenness of SH creates big fluctuations of jet stream, and in turn cause big weather anomalies. We are not addressing any single anomaly at synoptic scale, rather directly going to address patterns at a large scale. Such big scale can be understood only in a global level picture; available global information is not providing complete synoptic scale. But our filtering technology can reproduce global scales from existed information. We will examine the prevailing features of jet streams, especially in the spring and early summer and compare it with the tornado risks in this study.

\section{Data Source}

To investigate if and how jet stream associate to tornado development in the USA, we used hourly reanalysis- 
data “tavg1_2d_slv_Nx", from The Modern Era Retrospective-analysis for Research and Applications, National Aeronautics and Space Administration (MERRA/NASA). Hourly averages of zonal and meridional (u and v respectively) wind velocity components were available at $0.66667 \times 0.5$ degrees horizontal resolution and with 3 vertical levels at 250, 500 and $8500 \mathrm{hPa}$. MERRA covers the period 1979-present, continuing as an ongoing climate analysis as resources allow. As a pioneer study, this study will focus only on the period 1979-1988, at the vertical level of $250 \mathrm{hPa}$ over USA.

The hourly tornado dataset is derived from merging an hourly sequential data series with the "All Tornadoes" data (1950-2012) from the Storm Prediction Center, NOAA's National Weather Service

(http://www.spc.noaa.gov/wcm/\#data). National Weather Service provides comma separated value (.csv) files for tornado, hail, and damaging wind data as compiled from NWS Storm Data. Tornado reports exist back to 1950 while hail and damaging wind reports date from 1955.

\section{Methods}

In north hemisphere, the jet streams are located between the 400 and the $100 \mathrm{hPa}$ levels [8]. With substantial wind speed and elevation variations, jet streams are not continuous, they can break off at times and merge again "downstream" eventually; this makes it ambiguous and difficult to clearly identify jet stream's wind speed and boundaries at a given time [9]. Whereas, jet streams are located near the tropopause, air pressure p can be used to characterize the height of both the jet streams and the tropopause [8]. Therefore, we define the wind speed at $250 \mathrm{hPa}$ as the jet stream at any given location and time in this study:

$$
W S=\sqrt{u^{2}+v^{2}}
$$

where WS is the actual wind speed of jet stream at given time and location, $u$ is the eastward wind speed $(\mathrm{m} / \mathrm{s})$ at $250 \mathrm{hPa}, v$ is the northward wind speed $(\mathrm{m} / \mathrm{s})$ at $250 \mathrm{hPa}$.

Using hourly MERRA data, we calculate the daily maximum $\mathrm{WS}_{\mathrm{dmx}}$ for each grid at $0.66667 \times 0.5$ degrees horizontal resolution, ranging from $130^{\circ} \mathrm{W}$ to $65^{\circ} \mathrm{W}$ and $20^{\circ} \mathrm{N}$ to $50^{\circ} \mathrm{N}$. We then looked at the distribution of $\mathrm{WS}_{\mathrm{dmx}}$ by latitude and/or longitude; and compared it to the tornado risk distribution.

Applying KZ filter [10], we also smoothed latitudinal distribution of $\mathrm{WS}_{\mathrm{dmx}}$ at the selected longitude to compare their distribution between tornado days and non-tornado days.

$\mathrm{KZ}$ filter is a high resolution filter and its algorithm is simple to understand. It is known as a useful tool for time series analysis and has been widely used for trend separation [11], especially in meteorological air quality time series analysis [12]. Its mathematical form is $\mathrm{KZ}_{(\mathrm{m}, \mathrm{p})}$ :

$$
Y_{t}=\frac{1}{m} \sum_{s=-(m-1) / 2}^{(m-1) / 2} X(t+s)
$$

where $X$ is the input time series, and it is the time variable; parameter $m$ and $p$ is defined as $p$ iterations of a moving average filter of $\mathrm{m}$ points. The data series $Y$ becomes the input for the second iteration, and so on.

\section{Results}

\subsection{Seasonal Trends of Jet Stream}

We extracted the hourly eastward and northward wind speed at $250 \mathrm{hPa}$ from MERRA's 3D reanalysis database for each grid at the available horizontal resolution, for the period of 1979 to 1988. A 10-year average of WS, hereafter referred to as the jet stream wind speed, was calculated for each grid to plot the overall seasonal contour map of the jet stream.

Figure 2 shows wind maxima (dark blue) in spring to the Gulf of Mexico region, ranging from $120^{\circ} \mathrm{W}$ to $80^{\circ} \mathrm{W}$ and $22^{\circ} \mathrm{N}$ to $32^{\circ} \mathrm{N}$, to the region of North America beyond $40^{\circ} \mathrm{N}$ in summer, to the region of North-east America, over Maine State area in autumn, and to the region of East America, over North Carolina area in the winter. Seasonal difference and geographic patterns are substantial and clear: jet stream at $250 \mathrm{hPa}$ reaches to south in winter and spring; but it shifts northward back in summer and autumn. It is very interesting that jet streams were meandering with their average wind maxima located over the Mexican area in spring, which is the pike time around year for tornado to develop in Texas [7]. A consensus has emerged in viewing this consistence between tornado outbreaks and the wind maxima of jet stream. This suggests an association of tornado devel- 

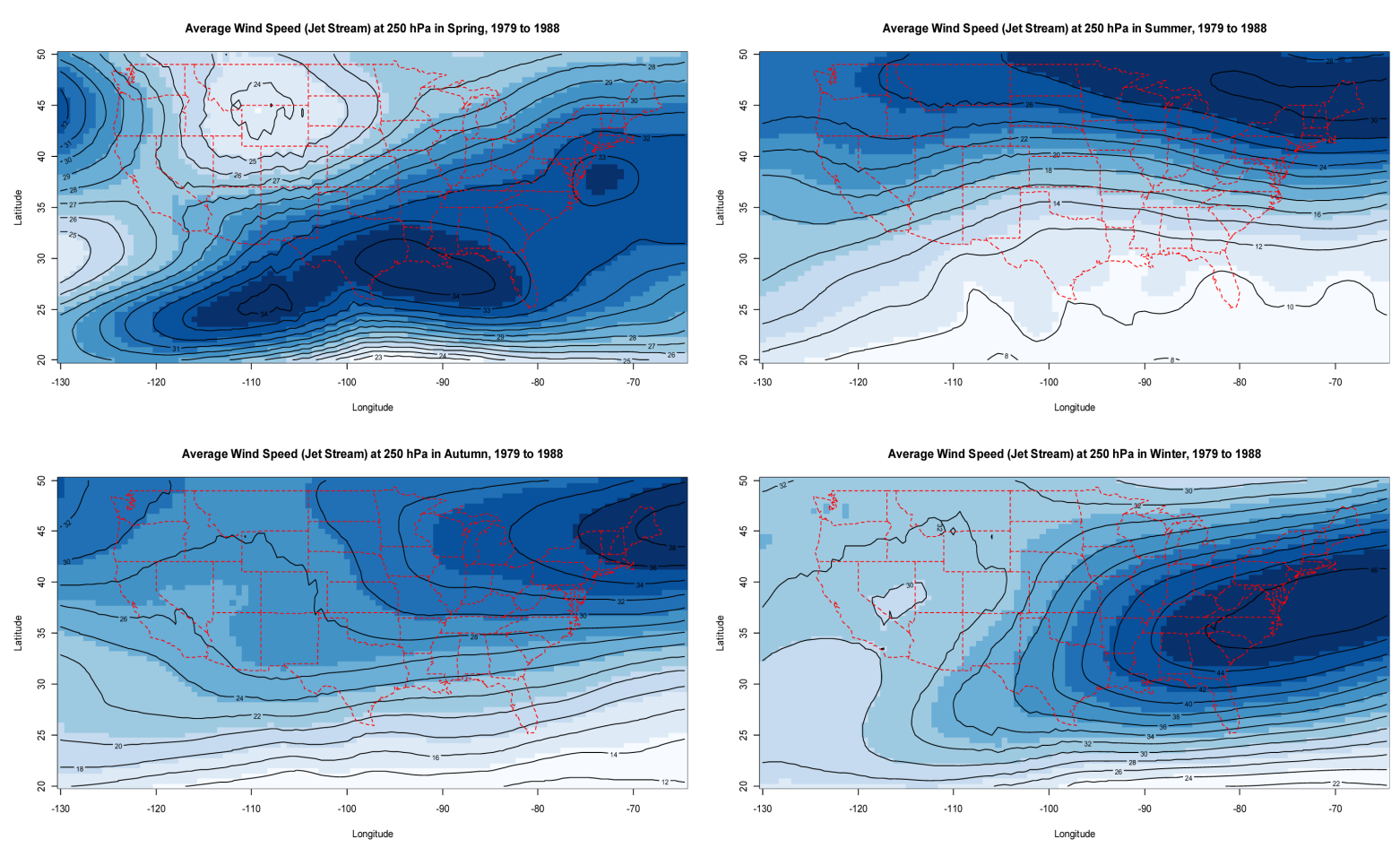

Figure 2. Average Trajectory of jet stream over USA.

opment with jet stream.

\subsection{Spatial Distribution of $\mathrm{WS}_{\mathrm{dmx}}$}

After generating the 3D matrix of WS at $250 \mathrm{hPa}$ for the study region, latitudinal distribution of $\mathrm{WS}_{\mathrm{dmx}}$ was calculated by longitude. Distribution of average $\mathrm{WS}_{\mathrm{dmx}}$ for the period of 1979 to 1988 was displayed in Figure 3. Daily wind maxima more frequently appeared to the lower latitudes in spring and winter (Figure 3, top panel); on the contrary, it appeared more frequently to the higher latitudes in summer, and scattered over the mid-latitudes in autumn. This can be explained by the varied seasonal transport properties of water vapor addressed above. While looking at the daily wind maxima's longitudinal distribution, it is impressive that $\mathrm{WS}_{\mathrm{dmx}}$ were more frequently detected over the regions from $130^{\circ} \mathrm{W}$ to $90^{\circ} \mathrm{W}$ in spring and winter; which were covering tornado alley area. Overall, there was a substantial higher probability for $\mathrm{WS}_{\mathrm{dmx}}$ to be observed in lower latitudes but skewed towards to eastward in spring and winter. Wind maxima of jet stream intensively detected in lower latitudes in spring involved in tornado development, perfectly explained by their timing and spatial concurrence respectively.

\subsection{Latitudinal Distribution of $\mathrm{WS}_{\mathrm{dmx}}$ by Month}

Overall frequency of marginal latitudinal $\mathrm{WS}_{\mathrm{dmx}}$ was calculated and plotted in Figure 4. Consistently more daily wind maxima were seen over the tornado alley (area between the two red lines) regions in November, December and January through May, especially in the lower latitudes; less daily wind maxima extremely skewed at lower latitudes was observed in July and August, and moderate number of daily wind maxima substantially skewed at lower latitudes was detected in other months (Figure 4). Although daily wind maxima were consistently hovering over the lower latitudes from January through May, probably it would not until ends of spring when the moisture water vapor were already heated up, especially in May, jet streams start substantially to contribute to tornado development. Its contributions to tornado development would last until it moved away toward North Pole; this is perfectly consistent with the distribution of tornado occurrence (Figure 5). On the other hand, in winter time (November, December, January and February), even though jet streams' wind speed peaked frequently over the lower latitude regions, it could not significantly trigger tornados due to lack of other factors, 

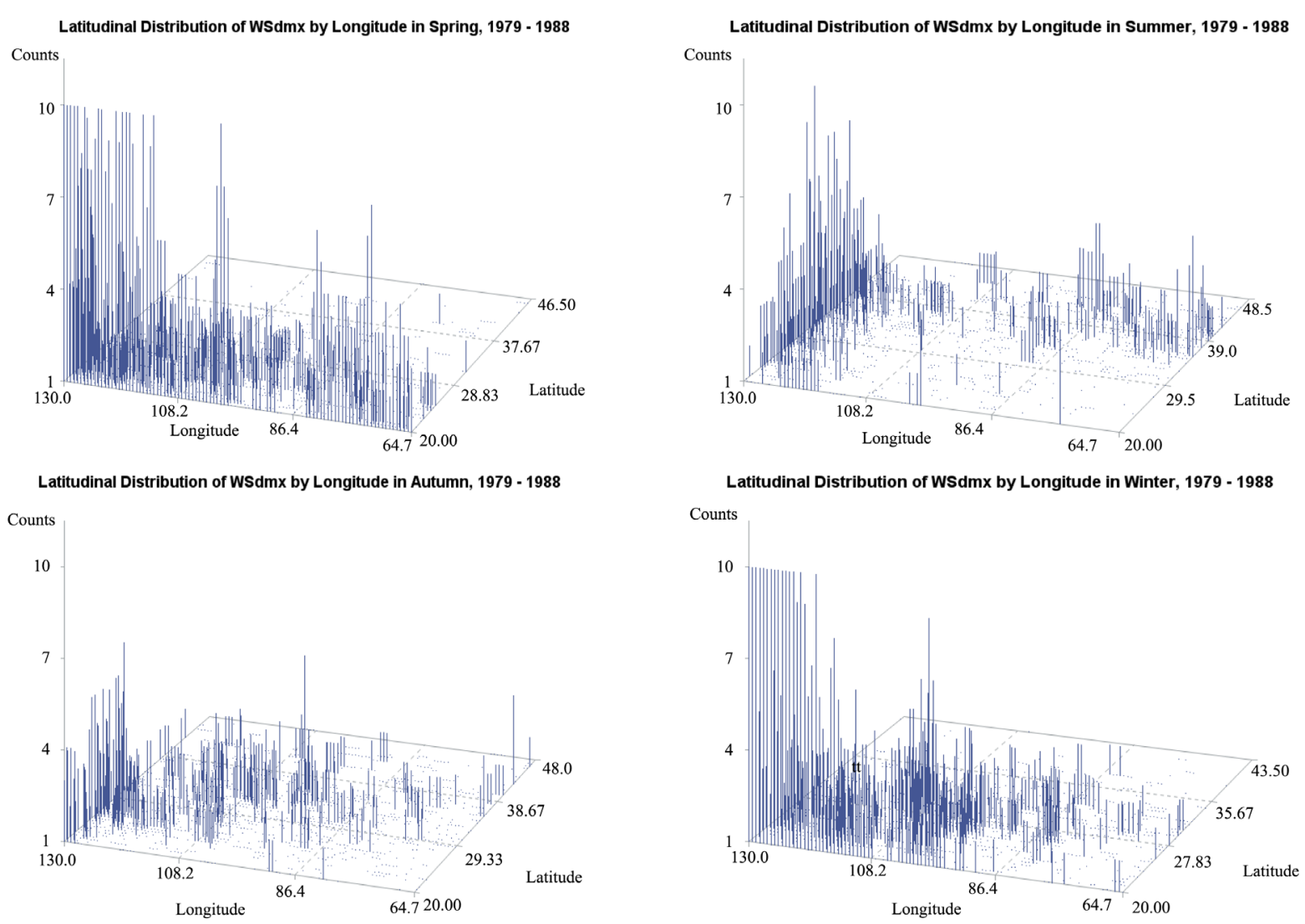

Figure 3. Spatial distributions of daily wind maxima at $250 \mathrm{hPa}$ over the study region: from $130^{\circ} \mathrm{W}$ to $65^{\circ} \mathrm{W}$ and from $20^{\circ} \mathrm{N}$ to $50^{\circ} \mathrm{N}$.

such as heated moisture vapor.

\subsection{Latitudinal Distribution of Tornados by Month}

Tornado development in USA (Figure 5 and Figure 6) showed a clear time pattern: most tornados developed in late spring and early summer. This is perfectly consistent with patterns of tornado occurrence in Texas from 1952 through 2008 [7]. Risks of tornado occurrence over our study region displayed a very typical monthly pattern, with the most tornados developed in April, May and June (Figure 5(a), Figure 6), and relatively very few tornados developed in the autumn and winter months (Figure 5(b), Figure 6). When stratified by a narrow time window "week", week 19 saw the highest number of tornados developed during 1979 to 1988, when compared with other weeks around the year, followed by weeks 18, 20 through 25 (Figure 6). A delayed effect of tornado development was obviously seen along with the latitudes rise. The number of tornado developed in April peaked at $34^{\circ} \mathrm{N}$, in June at $40^{\circ} \mathrm{N}$, in July at $43^{\circ} \mathrm{N}$, and in May with double peaks at $34^{\circ} \mathrm{N}$ and $42^{\circ} \mathrm{N}$ respectively. It perfectly indicated that the tornados came later at higher latitudes while jet streams were moving from lower to higher latitude regions.

\subsection{Comparison of Latitudinal Distribution of $\mathrm{WS}_{\mathrm{dmx}}$ between Tornado-Days and Non-Tornado-Days in the 19th-Week at Selected Longitude}

Given week 19 saw the highest number of tornados from 1979 through 1988, we select these days within week 19, on which any tornado developed as tornado-days; select other days within week 19, and days outside of, but closer to week 19 (in case there were not enough days, on which no tornado ever developed within week 19), without tornados developed as non-tornado days. We intended to compare the latitudinal distribution of $\mathrm{WS}_{\mathrm{dmx}}$ between tornado days and non-tornado days. To have a more precise comparison, we selected longitude $100^{\circ} \mathrm{W}$ 

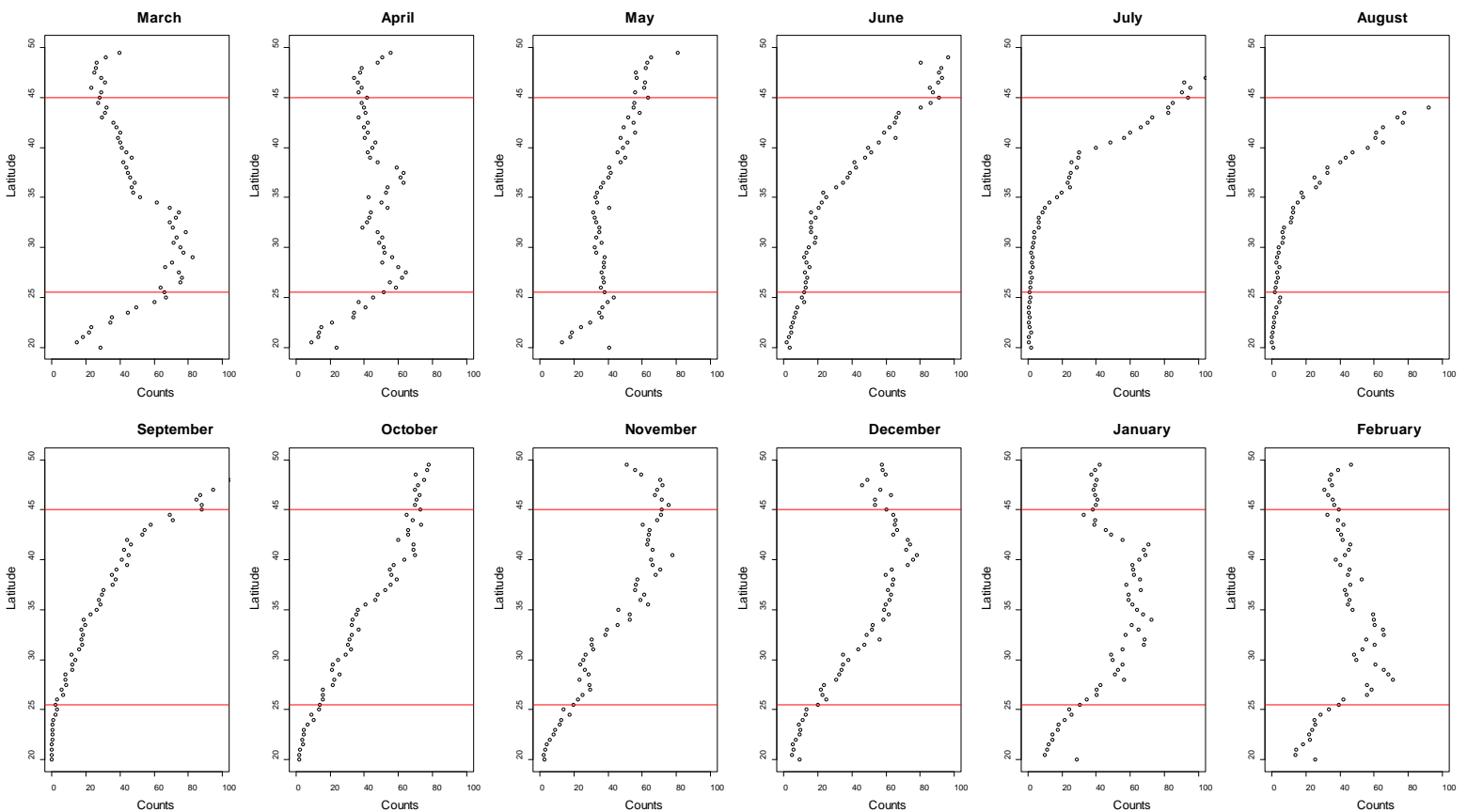

Figure 4. Distribution of $\mathrm{WS}_{\mathrm{dmx}}$ by month, 1979-1988.

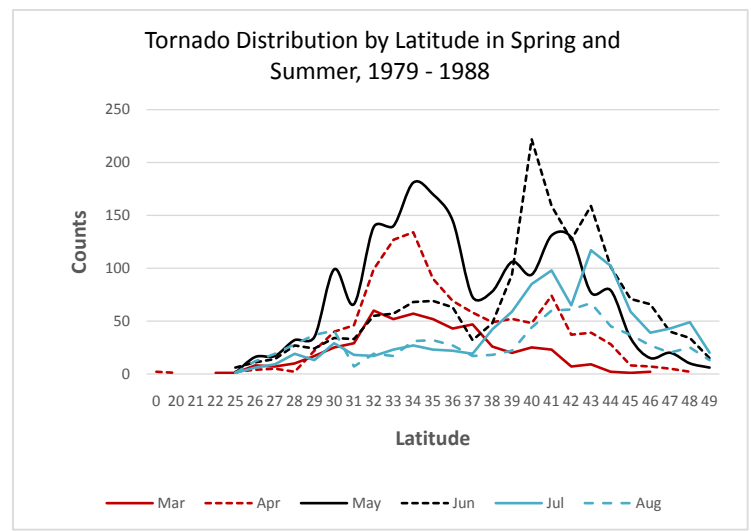

(a)

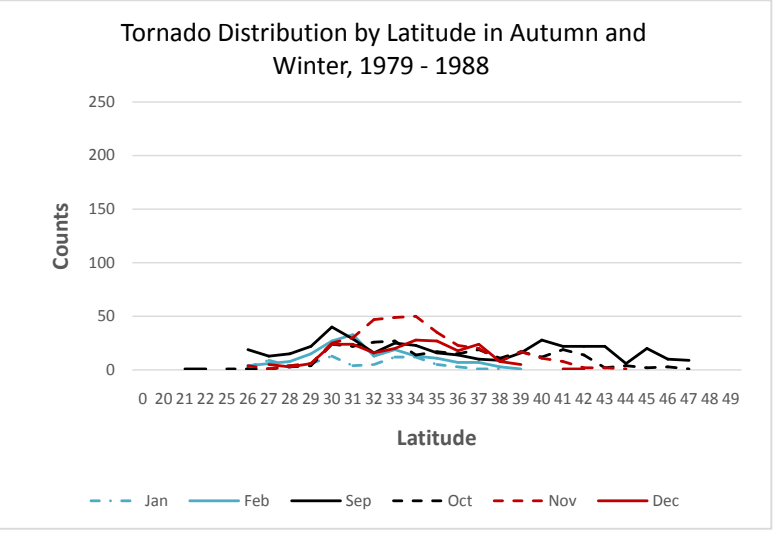

(b)

Figure 5. Latitudinal distribution of tornado outbreaks by month, from 1979 through 1988.

as our target zone; it is located about in the middle of tornado alley, we also used it as a reference line when we synchronized the geographic time in our previous study [7]. Finally, we calculated latitudinal distribution of $\mathrm{WS}_{\mathrm{dmx}}$ at $100^{\circ} \mathrm{W}$ for tornado days and non-tornado days (Figure 7).

To look at the latitudinal trends of $\mathrm{WS}_{\mathrm{dmx}}$ on tornado days at $100^{\circ} \mathrm{W}$, we smoothed the latitudinal distribution of $\mathrm{WS}_{\mathrm{dmx}}$ by using $\mathrm{KZ}_{(11,2)}$ filter. On tornado days within week 19 , we observed a big flat ridge in the mid-latitude regions, from $28^{\circ} \mathrm{N}$ to $36^{\circ} \mathrm{N}$. It indicated that during 1979 and 1988 , jet streams were meandering with more daily wind maxima appeared over this region on tornado days in week 19. In contrast, on non-tornado days in the same week, no significant higher number of wind maxima was observed over the same latitude regions compared with tornado days. This demonstrated that jet stream trigger tornado outbreaks when other factors available for tornado development.

\section{Summary}

Variations in longitude and season of water vapor are expected to affect transport of air mass poleward in the 


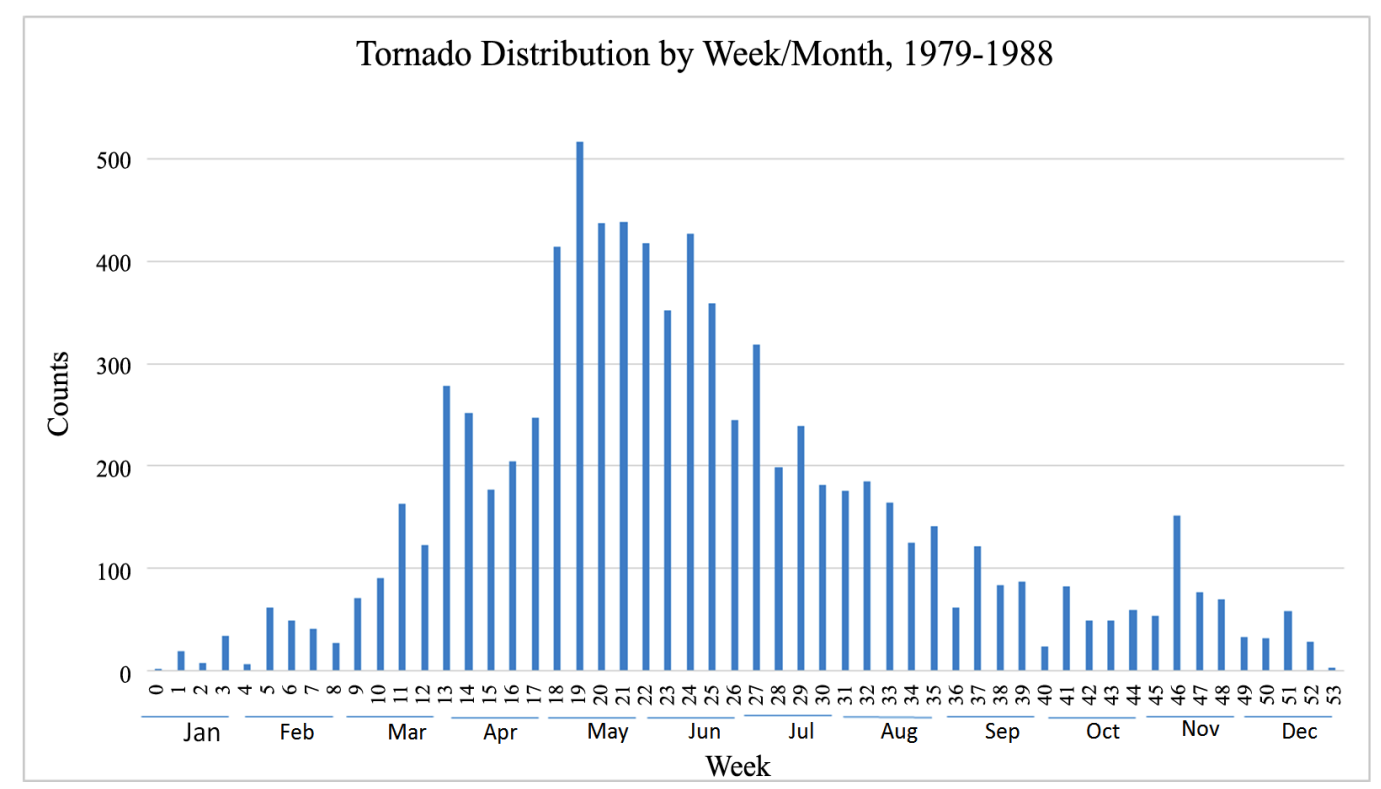

Figure 6. Weekly distribution of tornado occurrence from 1979 to 1988.
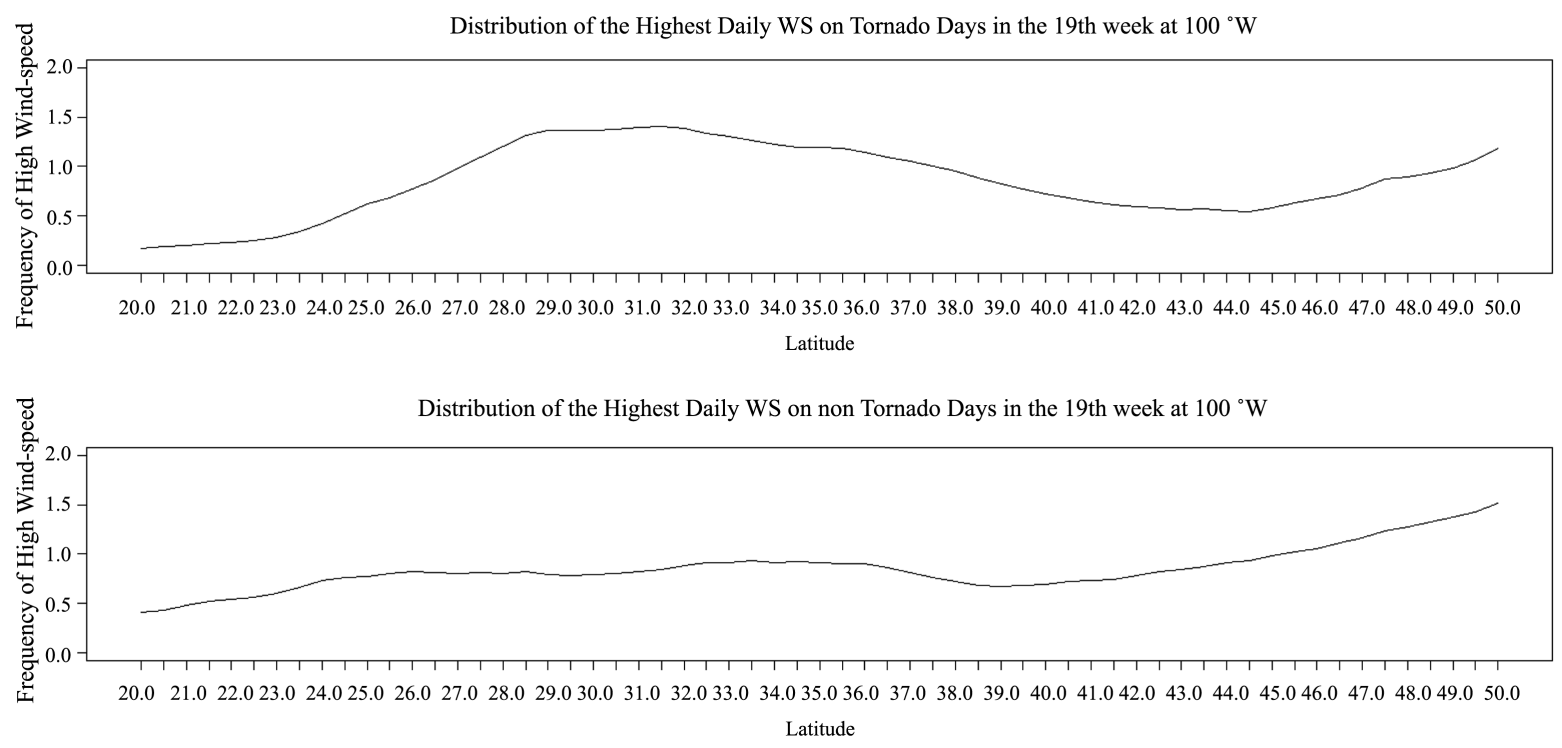

Figure 7. KZ smoothed distribution of the daily maximum WS in the $19^{\text {th }}$ week (tornado days vs non-tornado days), 19791988.

atmosphere and therefore affect the wind speed, direction and meandering trajectory of jet stream. Coupled with other factors, jet stream triggered tornado outbreak during the study period from 1979 through 1988; evidenced by: 1) jet stream was meandering over the tornado alley in the tornado seasons, in the late spring and early summer; 2) tornado outbreaks concurrently oscillated with monthly distribution of daily wind maxima in April, May and June; 3) comparisons of latitudinal $\mathrm{WS}_{\mathrm{dmx}}$ distribution between tornado days and non-tornado days in the $19^{\text {th }}$ week perfectly explained association of jet stream with tornado development.

Jet stream is only one of the key trigger factors; so it requires other factors' involvement to develop tornado. For example, in the winter time, even though jet stream was meandering over lower latitudes, but not many tornados developed, due at least partially, to lack of heated vapor in the atmosphere.

Overall, using our filtering technology in this study, we numerically addressed the appealing relationship between jet streams and tornado outbreaks in the Central America from 1979 through 1988. 


\section{Acknowledgements}

The authors would like to thank Professor Cristina L. Archer at University of Delaware, Dr. Michael G. Bosilovich at National Aeronautics and Space Administration, Professor Fangqun Yu, Professor Junhong Wang and Ph.D. student Geng Xia at SUNY Albany for the help with downloading and reading MERRA data.

\section{References}

[1] Zurbenko, I.G. and Luo, M. (2015) Surface Humidity Changes in Different Temporal Scales. American Journal of Climate Change, 4, 226-238.

[2] Zurbenko, I.G. and Potrzeba, A.L. (2013) Tides in the Atmosphere. Air Quality, Atmosphere \& Health, 6, 39-46. http://dx.doi.org/10.1007/s11869-011-0143-6

[3] National Weather Service. JetStream-Online School for Weather. http://www.srh.noaa.gov/jetstream/tstorms/tornado.htm

[4] Premium Weather. The Jet Stream-Upper Air Flow and Severe Weather. http://www.tornadochaser.net/jet.html

[5] AccuWeather (2011) 150-mph Jet Stream a Key Factor in Wednesday’s Tornado Outbreak. http://www.accuweather.com/en/weather-news/150mph-jet-a-key-factor-in-wed/48985

[6] Livescience (2011) Deadly Tornadoes, Floods Blamed on “Superjet” Stream. http://www.livescience.com/30952-alabama-tornadoes-tennessee-floods-superjet-stream.html

[7] Zurbenko, I.G. and Sun, M.Z. (2014) High Risk Periods in Tornado Outbreaks in Central USA. Advance in Research, 2, 426-440. http://dx.doi.org/10.9734/AIR/2014/10247

[8] Archer, C.L. and Caldiera, K. (2008) Historical Trends in the Jet Streams. Geophysical Research Letters, 35, Article ID: L08803.

[9] Koch, P., Weirnli, H. and Davies, H.C. (2006) An Event-Based Jet-Stream Climatology and Typology. International Journal of Climatology, 26, 283-301. http://dx.doi.org/10.1002/joc.1255

[10] WIKIPEDIA. Kolmogorov-Zurbenko Filter. https://en.wikipedia.org/wiki/Kolmogorov\%E2\%80\%93Zurbenko_filter\#

[11] DiRienzo, G., Zurbenko, I. and Carpenter, D. (1998) Time Series Analysis of Aplysia Total Motion Activity. Biometrics, 54, 493-508. http://dx.doi.org/10.2307/3109758

[12] Yang, W. and Zurbenko I. (2010) Kolmogorov-Zurbenko Filters. Wiley Interdisciplinary Revives in Computational Statistics, Wiley, WIREs in Computational Statistics, 2, 340-351. http://wires.wiley.com/WileyCDA/WiresArticle/wisId-WICS71.html 